\section{Detection of food hazards in foods: comparison of real time polymerase chain reaction and cultural methods}

\author{
Paolo Bonilauri,' Lia Bardasi, ${ }^{1}$ \\ Roberto Leonelli,' Mattia Ramini,' \\ Andrea Luppi, ${ }^{1}$ Federica Giacometti, ${ }^{2}$ \\ Giuseppe Merialdi ${ }^{1}$ \\ ${ }^{1}$ Institute for Experimental Veterinary \\ Medicine of Lombardy and Emilia \\ Romagna, Brescia; ' 2 Department of \\ Veterinary Sciences, Alma Mater \\ Studiorum-University of Bologna, \\ Bologna, Italy
}

genes, and thermophilic Campylobacter in 2.18, 3.85 and $3.73 \%$ of the samples, respectively, whereas by using cultural method these pathogens were isolated in $0.43,1.57$ and $1.57 \%$ of samples, respectively. In spite of the use of the same enrichment broth, the RT-PCR method disclosed a percentage of positive samples that was negative to cultural examination ranging between 20 and $43 \%$, with a PCR/culture ratio between 2.37 to 5.00 . In conclusion, the results of this study pose a doubt about the sensitivity of the official cultural methods regarding the isolation of the three investigated foodborne pathogens. Moreover this study may be a useful tool for veterinary authorities to assess appropriate sampling plans to control the risk relating to the consumption of contaminated foods.

\section{Introduction}

Foodstuffs should not contain microorganisms or their toxins or metabolites in quantities suggesting an unacceptable risk for human health. The detection of food hazards in foods is performed by several tests that produce results dependent on the analytical method used: an analytical reference method, defined as standard, is associated with each microbiological criterion laid down in Regulation 2073/2005/EC, but, analytical methods other than the reference ones, in particular more rapid methods, could be used. Combined screening methods performed by real time-polymerase chain reaction (RT-PCR) are currently validated as alternative methods according to the ISO 16140:2003 and certified by the Association Française de Normalisation. However, the positive results obtained with these alternative methods, the investigated molecular relations that resulted positive have to be confirmed with cultural methods using the same enrichment media in which the molecular screening was performed. Since it is necessary to assess if these testing schemes provide equivalent guarantees of food safety, the aim of this retrospective study is to analyse the data collected, from 2012 to 2014 by Emilia Romagna Region in the field of Piano Regionale Alimenti (Food Regional Plan) during official controls monitoring food samples of animal and other than animal origin. Records performed by combined methods of molecular screening of Salmonella spp., Listeria monocytogenes and thermophilic Campylobacter and cultural confirmation results were gathered together and the results were compared in order to assess the sensitivity of the methods. A total of 10,604 food samples were considered in this study: the comparison of the data revealed that the RT-PCR method detected Salmonella, L. monocyto-
Microbiological methods are well established in food pathogen detection and very reliable to a certain degree; these methods are based on the growth of the target organisms as a means of obtaining the required magnification for macroscopic observation by the researcher. The occurrence of a colony is interpreted as meaning that at least a single living organism was present in the original sample (Rossmanith and Wagner, 2010).

Given the likelihood that microorganisms are able to grow on cultural media, microbiological methods theoretically detect one viable microbial cell in each food product sample, meaning a portion of food to be analysed, but the real sensitivity of these methods depend on factors related both to the food matrix (unprocessed or processed, fresh, refrigerated, frozen, fermented, etc.) and to the bacteria [bacteria in lag phase, cells able to divide, viable but non-cultivable (VBNC) cells and dead ones]. The concept of viability of microorganisms was for long considered as the ability to multiply on an optimal medium (Postgate et $a l ., 1961)$ but it is now universally recognised that many intermediate phases exist between live and dead bacteria and that colonies recovered by application of a cultural method correspond to the cells (or groups of cells) that are able to replicate under the provided growth conditions (Sohier et al., 2014). Traditionally, descriptive cultural methods have been used, and remain the most employed to determine the presence/absence of colonies (i.e., cultivable cells) and their numbers. However, these straightforward methods provide a very simplistic, often biased, view of the physiological state of microbial populations in which several subpopulations characterised by various levels of viability and metabolic activity may coexist (Davey, 2011). The emergence of
Correspondence: Federica Giacometti,

Department of Veterinary Sciences, Alma Mater Studiorum-University of Bologna, via Tolara di Sopra 50, 40064 Ozzano Emilia (B0), Italy. Tel: +39.051.2097320 - Fax: +39.051.2097346. E-mail: federica.giacometti3@unibo.it

Key words: Real time PCR; Cultural methods; Analytical sensitivity; Food matrices.

Conflict of interest: the authors declare no potential conflict of interest.

Received for publication: 23 November 2015. Revision received: 10 December 2015.

Accepted for publication: 11 December 2015.

This work is licensed under a Creative Commons Attribution-NonCommercial 4.0 International License (CC BY-NC 4.0).

(C) Copyright P. Bonilauri et al., 2016 Licensee PAGEPress, Italy

Italian Journal of Food Safety 2016; 5:5641 doi:10.4081/ijfs.2016.5641

molecular techniques has opened new opportunities to characterise the numerous intermediate states of microbial cells, so much so that the wellbeing, fitness, and metabolic activities are now being targeted through the quantification of biomarkers, rather than just growth/no growth quantifications (Sieuwerts et al., 2008; de Vos, 2011).

The direct molecular methods allow the detection of DNA of foodborne pathogens directly from the food matrix without the need of cultural media; the sample preparation for these techniques needs some steps as sample homogenisation, DNA extraction and in vitro amplification of DNA target by polymerase chain reaction (PCR) or real time-PCR (RTPCR). However, even in case of higher sensitivity methods like real time PCR, the direct methods have a low analytical sensitivity, and, for example Rudi et al. (2005) used the DNAeasy ${ }^{\circledR}$ tissue kit (Qiagen, Valencia, CA, USA), DNA DIRECT ${ }^{\circledR}$ (Dynal AS, Oslo, Norway), to extract DNA from Gouda cheese for subsequent detection of $L$. monocytogenes with real-time PCR, obtaining a detection limit of $3.2 \times 102 \mathrm{CFU} \mathrm{g}^{-1}$. These results highlight the limit of direct DNA isolation, in fact the obtained detection limit results higher than the natural contaminations level in food samples. In addition, these methods could perform differently depending on sample preparation, amplification and data expression, which may have a major impact on the results. The lack of consensus on how best to perform experiments and interpret PCR data is regularly pointed out (Bustin, 2009; Boyer and Combrisson, 2013).

Due to these drawbacks and limitations, 
direct molecular methods have not been applied to the routine analysis of microbiological criteria laid down in terms of food safety but are actually restricted to reserch activities with the main aim to quantify fastidious microorganisms or difficult to isolate. The combination of traditional microbiological enrichment approach and molecular pathogen detection could be useful to increase the advantages of both methods and decrease their disadvantages. So the detection limit of qPCR is far exceeded after successful enrichment. Short enrichments if performed in an appropriate way are mostly sufficient to provide enough DNA for detection, and the confirmation of the identification of the pathogen is made during the detection step.

Combined screening methods by RT-PCR are currently validated as alternative methods according to the ISO 16140:2003 (ISO, 2003) and certified by the Association Française de Normalisation (AFNOR); with these alternative methods, the investigated molecular relations that resulted positive have to be confirmed with cultural methods using the same enrichment media in which the molecular screening is performed; this fact is useful to avoid both sampling and homogenisation steps of the food sample preparation.

However, the possibility that positive screening results performed by molecular methods were not later confirmed by cultural methods is amply reported during routine food analyses and this could be due to non-specific reactions that occur in the different food matrices or enrichment broths, cross-reaction of the investigated DNA target with similar taxonomic microorganisms, presence of VBNC cells or dead cells but in concentration that anyway resulted quantifiable by molecular methods. The aim of this retrospective study is to analyse the data collected in the field of Food Regional Plan [Piano Regionale Alimenti (PRA)], performed in Emilia Romagna Region that gathered together records performed by combined methods of molecular screening of Salmonella spp., Listeria monocytogenes and thermophilic Campylobacter and cultural confirmation results, during official controls monitoring food samples, of animal origin and non, from 2012 to 2014 .

\section{Materials and Methods}

In the field of PRA performed in Emilia Romagna Region, Official Veterinary Services and Sistema Informativo Agricolo Nazionale (SIAN) performed official samplings of different food matrices according to Regulation (EC) 2073:2005 (European Commission, 2005), when applicable. All the collected sample units that were processed by the Experimental Institutes for Zooprophylaxis in Lombardy and Emilia Romagna Region, sections of Bologna and Reggio Emilia, were analysed applying alternative molecular methods validated by AFNOR:ISO-16140, by RT-PCR, and, specifically by using the kit iQ-Check ${ }^{\circledR}$ Bio-Rad, the CFX96 Bio-Rad instrument and Bio-Rad CFX Manager Industrial Edition 1.1 software. In agreement with each validated method, in case of positive RT-PCR result, the same enrichment broth, used for molecular analysis, was applied to perform traditional microbiological confirmation in accordance with the official ISO cultural methods [ISO 6579:2002/C1:2004 (ISO, 2004b), ISO 11290-
1:1996/AM1:2004 (ISO, 2004a), ISO 102721:2006 (ISO, 2006), respectively for Salmonella, L. monocytogenes and thermophilic Campylobacter]. All the positive records of both molecular and cultural methods were collated and used to assess the rate of microbiological confirmation obtained in the different food matrices analysed.

\section{Statistical analysis}

The frequency of coltural confirmations out of DNA detection of Salmonella, L. monocytogenes and Campylobacter by RT-PCR per year of data analysis, was compared using test Chi square with Intercooled Stata 7.0 software (Stata Corporation, College Station, TX, USA). Significance was established at $\mathrm{P}<0.05$.

\section{Results}

From 2012 to 2014, a total of 10,604 samples that satisfied the inclusion criteria were considerided: 5982 for Salmonella (2086, 2208, 1688 sample units tested in 2012, 2013 and 2014 respectively), 4133 for $L$. monocytogenes (1440, 1517, 1176 sample units tested in 2012, 2013, 2014 respectively) and 509 for thermophilic Campylobacter (276, 132, 101 sample units tested 2012, 2013 and 2014 respectively) (Table 1).

Table 2 summarises the results of the official monitoring over the 3 -year period, including the number of samples tested per year and per microrganism and the number and percentage of positive samples, both by RT-PCR screening and cultural isolation.

Statistical analysis showed that the overall rate of confirmation (percentage of microbio-

Table 1. Number of samples analysed per year and number and percentage of positive samples as determined by the real time polymerase chain reaction and cultural methods.

\begin{tabular}{|c|c|c|c|c|c|c|c|c|c|}
\hline & & Salmonella & & & teria monocytoge & nes & The & 10philic Campylo & bacter \\
\hline Year & $\begin{array}{c}\text { Total } \\
\text { analysed } \\
\text { samples }\end{array}$ & $\begin{array}{l}\text { No. of samples } \\
\text { positive by } \\
\text { real time PCR }\end{array}$ & $\begin{array}{l}\text { No. of samples } \\
\text { positive by } \\
\text { ISO culture }\end{array}$ & $\begin{array}{c}\text { Total } \\
\text { analysed } \\
\text { samples }\end{array}$ & $\begin{array}{l}\text { No. of samples } \\
\text { positive by } \\
\text { real time PCR }\end{array}$ & $\begin{array}{l}\text { No. of samples } \\
\text { positive by } \\
\text { ISO culture }\end{array}$ & $\begin{array}{c}\text { Total } \\
\text { analysed } \\
\text { samples }\end{array}$ & $\begin{array}{c}\text { No. of samples } \\
\text { positive by } \\
\text { real time PCR }\end{array}$ & $\begin{array}{c}\text { No. of samples } \\
\text { positive by } \\
\text { ISO culture }\end{array}$ \\
\hline 2012 & 2.086 & $30(1.43)$ & $8(0.38)$ & 1.440 & $58(4.02)$ & $26(1.80)$ & 276 & $8(2.89)$ & $3(1.08)$ \\
\hline 2013 & 2.208 & $45(2.03)$ & $9(0.40)$ & 1.517 & $55(3.62)$ & $22(1.45)$ & 132 & $7(5.30)$ & $4(3.03)$ \\
\hline 2014 & 1.688 & $55(3.25)$ & $9(0.53)$ & 1.176 & $37(3.14)$ & $17(1.44)$ & 101 & $4(3.96)$ & $1(0.99)$ \\
\hline
\end{tabular}

PCR, polymerase chain reaction; ISO, International Organization for Standardization. Values in parentheses are expressed as percentage.

Table 2. Total number of samples analysed in three years of monitoring and number and percentage of positive samples as determined by real rime polymerase chain reaction and cultural methods.

\begin{tabular}{lccc} 
Evaluation & Salmonella & Listeria monocytogenes & Thermophilic Campylobacter \\
Total no. of samples analysed & 5962 & 4133 & 509 \\
No. of samples positive by PCR & $130(2.18)$ & $159(3.85)$ & $19(3.73)$ \\
\hline No. of samples positive by culture & $26(0.43)$ & $65(1.57)$ & $8(1.57)$ \\
PCR/culture ratio & 5.00 & 2.44 & 2.37 \\
\hline
\end{tabular}

PCR, polymerase chain reaction. Values in parentheses are expressed as percentage. 
logical isolation on positive reactions in RTPCR screening methods) for Salmonella and $L$. monocytogens do not differed significantly $(\mathrm{P}>0.05)$ in three-year monitoring, whereas, for Campylobacter the few data available do not allowed any comparison. The comparison of the data from 3 years analysed in parallel by the cultural method and the RT-PCR method revealed that the RT-PCR method detected Salmonella, L. monocytogenes, and thermophilic Campylobacter in 2.18, 3.85 and $3.73 \%$ of the samples, respectively, whereas the cultural method detected these pathogens in $0.43,1.57$ and $1.57 \%$ of samples, respectively. With regard to Salmonella, all the cultural confirmation of positive RT-PCR screening (20\%) belong to raw meat samples (chicken, turkey and pork), whereas the positive RT-PCR screening food matrices not confirmed by cultural methods were represented by cooked meats, drinks, eggs, cured meats, sweets, chocolate, fruits and infant formula foods.

With regard to L. monocytogenes, $43 \%$ of positive RT-PCR screenings resulted confirmed also by cultural methods; the food matrices were raw meats and ready-to-eat (RTE) products (90\%) and cooked foods (10\%). Unfortunately, no correlation could be assessed between the probability of isolation with the concentration of the microorganism in the food sample because the $86 \%$ of the confirmed cases were under the quantification limit (LoQ) of the method and the last 14\% resulted $<100 \mathrm{cfu} / \mathrm{g}$. Finally, Campylobacter were confirmed by microbiological methods in the $42 \%$ of the cases; for this pathogen only raw meet samples were analysed.

\section{Discussion}

This retrospective study confirms the wellreported higher sensitivity of the RT-PCR versus cultural method (Karns et al., 2005; Chapman et al., 2001; Yang et al., 2003; Aznar and Solis, 2006; Wegmüller et al., 1993); in fact, our results show that, in spite of the use of the same enrichment broth, the RT-PCR method disclosed a percentage of positive samples that were negative to cultural examination ranging between 20 and $43 \%$, with a $\mathrm{PCR} /$ culture ratio between 2.37 to 5.00 .

As emphasised by Chapman et al. (2001), the different sensitivity of methods is probably due to the low level of contamination of pathogens in food samples, and, in the case of a very low concentration of bacteria, the probability of finding a pathogen is very low to negligible and even the detection by PCR of samples with low numbers of the microorganism but containing high numbers of competing microorganisms has often lacked sensitivity (Niroomand and Lord, 1994; Weagent et al.,
1995; Firstenberg and Sullivan, 1997). The standard volume of sample analysed in a qualitative cultural method is usually $25 \mathrm{~mL} / \mathrm{g}$, and its sensitivity is usually assumed to be 1 cell in $25 \mathrm{~mL}$ or $25 \mathrm{~g}$, and, PCR-based methods being about 10 times more sensitive, are considered able to detect 0.1 cell in $25 \mathrm{~mL}$.

Considering that the pertinent levels of detection in foods processed for safety are often extremely low (e.g. $1 \mathrm{cfu} \mathrm{kg}^{-1}$ or $\left.^{-1}\right)$ and that these low concentrations have sometimes to be isolated amongst high level of indigenous microflora (exceeding the target organism by a factor of up to $10^{6}$, especially in fresh commodities), sometimes the erratically distribution of microorganisms in the vast majority of foods could deprive negative results of tests significance (Habraken et al., 1986).

Problems surrounding highly selective enrichment and isolation procedures are compounded by the observation, made, for the first time by Eijkman (1908), that the majority of microrganisms of significance in foods have incurred sublethal lesions as a result of having been exposed to adverse external conditions (directly injurious like heating or indirectly as lowered food $\mathrm{pH}$ or aw and sometimes even both). If highly selective procedures, including the use of particular antimicrobial molecules or increased incubation temperature, are applied to such debilitated populations, the combined stress will result in cell death, causing erroneously low results (Sallam and Donnelly, 1992; Morinigo et al., 1993).

A major pitfall on the use of molecular microbiology methodology is related to the nature of foods themselves; methods that work remarkably well with pure cultures of target microorganisms failed initially when applied to real word specimens (Patel, 1994). This was observed also in our study when fat matrix such as cacao, chocolate, eggs yolk and sweet were never confirmed microbiologically after positive reaction in RT-PCR for the presence of Salmonella DNA.

Moreover, the presence in many foods of contaminating inhibitory material and the occurrence of such so-called PCR inhibitors, which comprise all substances that have a negative effect on the PCR, is a major drawback of the PCR (Scharder et al., 2012). PCR inhibitors can originate from the sample or may be introduced during sample processing or nucleic acid extraction. The major consequence of a partly or total inhibition of the PCR is a decreased sensitivity or false-negative results, respectively. One certain matrix may contain many different inhibitory substances and the same inhibitors can be found in many different matrices (Scharder et al., 2012). For example, Malorny et al. (2003) suggested the presence of PCR inhibitors in the PCR reaction of 8 out of 435 samples which were initially negative by PCR but positive by traditional cultural method. Several strategies have been developed to remove PCR inhibitors during sample preparation; however, preparations free of PCR inhibitors cannot be guaranteed,especially in complex matrices; as a result, all reactions should be analysed for the presence of inhibitory effects (Scharder et al., 2012). In our study all the samples were checked for the presence of inhibitors through the internal control provided by the kit used ruling out false negative results.

\section{Conclusions}

In conclusion, this study allows to compare the results of RT-PCR in parallel with cultural methods, questioning the sensitivity of the official cultural methods of the three investigated foodborne pathogens and the relative risks associated with human consumption. This study may be a useful tool for Veterinary Authorities to assess appropriate sampling plans to control the risk of acquiring foodborne pathogens from the consumption of contaminated foods.

\section{References}

Aznar R, Solis I, 2006. PCR detection of Listeria monocytogenes in different food products compared with the mini-VIDAS LMO system and the standard procedure ISO 11290-1. J Verbrauch Lebensm 1:115-20.

Boyer M, Combrisson J, 2013. Analytical opportunities of quantitative polymerase chain reaction in dairy microbiology. Int Dairy $\mathrm{J}$ 30:45-52.

Bustin SA, Benes V, Garson JA, Hellemans J, Huggett J, Kubista M, Mueller R, Nolan T, Pfaffl MW, Shipley GL, Vandesompele J, Wittwer CT, 2009. The MIQE guidelines: minimum information for publication of quantitative real-time PCR experiments. Clin Chem 55:611-22.

Chapman PA, Ellin M, Ashton R, Shafique W, 2001. Comparison of culture, PCR and immunoassays for detecting Escherichia coli 0157 following enrichment culture and immunomagnetic separation performed on naturally contaminated raw meat products. Int J Food Microbiol 68:1120.

Davey HM, 2011. Life, death, and in-between; meanings and methods in microbiology. Appl Environ Microb 77:5571-6.

de Vos WM, 2011. Systems solutions by lactic acid bacteria: from paradigms to practice. Microb Cell Fact 10(Suppl.1):S2.

Eijkman C, 1908. Die Ueberlebungskurve bei Abtotung von Bakterien durch Hitze. 
Biochem Zeitschr 11:1007-10.

European Commission, 2005. Commission Regulation of 15 November 2005 on microbiological criteria for foodstuffs, 2073/2005/EC. In: Official Journal, L 388/1, $22 / 12 / 2005$.

Firstenberg ER, Sullivan NM, 1997. E. coli rapid detection system: a rapid method for the detection of Escherichia coli 0157 in meat and other foods. J Food Protect 60:219-25.

Habraken CJM, Mossel DAA, Van Den Reek S, 1986. Management of salmonella risks in the production of powdered milk products. Neth Milk Dairy J 40:99-116.

ISO, 2003. Microbiology of food and animal feeding stuffs. Protocol for the validation of alternative methods. ISO Norm 16140:2003. International Organization for Standardization, Geneva, Switzerland.

IS0, 2004a. Microbiology of food and animal feeding stuffs. Horizontal method for the detection and enumeration of Listeria monocytogenes. Part 1: Detection method; Amendment 1: Modification of the isolation media and the haemolysis test, and inclusion of precision data. ISO Norm 11290-1:1996/AM1:2004. International Organization for Standardization, Geneva, Switzerland.

ISO, 2004b. Microbiology of food and animal feeding stuffs. Horizontal method for the detection of Salmonella spp. ISO Norm 6579:2002/C1:2004

Technical Corrigendum $1 . \quad$ International Organization for Standardization, Geneva, Switzerland.
ISO, 2006. Microbiology of food and animal feeding stuffs. Horizontal method for detection and enumeration of Campylobacter spp. Part 1: Detection method. ISO Norm 10272-1:2006. International Organization for Standardization, Geneva, Switzerland.

Karns JS, Van Kessel JS, McClusjey BJ, Perdue ML, 2005. Prevalence of Salmonella enterica in bulk tank milk from US dairies as determined by polymerase chain reaction. J Dairy Sci 88:3475-9.

Malorny B, Hoorfar J, Hugas M, Heuvelink A, Fach P, Ellerbroek L, Bunge C, Dorn C, Helmuth R, 2003. Interlaboratory diagnostic accuracy of a Salmonella specific PCR-based method. Int J Food Microbiol 89:241-9.

Morinigo MA, Munoz MA, MartinezManzanares E, 1993. Laboratory study of several enrichment broths for the detection of Salmonella spp. particularly in relation to water samples. J Appl Bacteriol 74:330-5.

Niroomand F, Lord C, 1994. Comparison of rapid techniques for teh detection of Escherichia coli 0157:H7. J Rapid Methods Autom Microbiol 3:85-96.

Patel P, 1994. Rapid analysis techniques in food microbiology. Chapman \& Hall, London, UK.

Postgate JR, Crumpton JE, Hunter JR, 1961. The measurement of bacterial viabilities by slide culture. J Gen Microbiol 24:15-24.

Rossmanith P, Wagner M, 2010. The challenge to quantify Listeria monocytogenes: a model leading to new aspects in molecular biological food pathogen detection. J Appl
Microbiol 110:605-17.

Rudi K, Naterstad K, Dromtorp SM, Holo H, 2005. Detection of viable and dead Listeria monocytogenes on gouda-like cheeses by realtime PCR. Lett Appl Microbiol 40:301-6.

Sallam SS, Donnelly CW, 1992. Destruction, injury and repair of Listeria species exposed to sanitizing compounds. J Food Protect 55:771-6.

Schrader C, Schielke A, Ellerbroek L, Johne R, 2012. PCR inhibitors: occurrence, properties and removal. J Appl Microbiol 113: 1014-20.

Sieuwerts S, De Bok FA, Hugenholtz J, Van Hylckama Vlieg JE, 2008. Unraveling microbial interactions in food fermentations: from classical to genomics approaches. Appl Environ Microb 74:49975007.

Sohier D, Pavan S, Riou A, Combrisson J, Postollec F, 2014. Evolution of microbiological analytical methods for dairy industry needs. Front Microbiol 5:16.

Weagent SD, Bryant JL, Jinneman KC, 1995. An improved rapid technique for isolation of Escherichia coli 0157:H7 from food. J Food Protect 58:7-12.

Wegmüller B, Lüthy J, Candrian U, 1993. Direct polymerase chain reaction detection of Campylobacter jejuni and Campylobacter coli in raw milk and dairy products. Appl Environ Microb 59:2161-5.

Yang C, Jiang Y, Huang K, Zhu C, Yin Y, 2003. Application of real-time PCR for quantitative detection of Campylobacter jejuni in poultry, milk and environmental water. FEMS Immunol Med Mic 38:265-71. 